\title{
Partnership, conflict and gaming
}

\author{
Jacky Lumby* and Marlene Morrison \\ University of Lincoln, UK
}

Government policy stresses partnership as a critical organizational form of the future to support the development of schooling. This article uses intergroup conflict and gaming theory to analyse data from one partnership. The views of young people and staff are explored to establish the nature and extent of conflict and its impact on the partnership. Gaming theory is used to investigate the engagement and expectations of organizations in the partnership. The article challenges Government rhetoric that suggests that as experience and trust grow, partnership will overcome the barriers which exist as a legacy from previous more competitive and isolationist cultures, to the benefit of service users. It further suggests that the availability of adequate resources alone, if ever achieved, would not in itself create the conditions for successful partnership. Far more attention is required to be given to the complex range of conditions which might support partnership and increase the possibility that the interests of learners would not be subordinated to those of organizations.

\section{Introduction}

UK Government policy since the mid-1990s has repeatedly promoted the idea of 'partnership' as a means of improving the performance of public sector organizations. In education, initiative after initiative foregrounds partnership as a key strategy, either explicitly in the title, for example, the Leading Edge Partnership Programme, the Learning Partnership, Partnership Working, or implicitly through setting up collaborative arrangements such as Education Actions Zones and Excellence in Cities. Policy and initiative statements, however, are either silent or very general on what is meant by partnership. In response, as unspecified notions of 'partnership' burgeon in the public sector, research has attempted to categorize the different arrangements which are labelled as partnership (Furlong et al., 1996; Lowndes \& Skelcher, 1998; Griffiths, 2000). It has also been concerned to explore the perspectives of those involved to deduce not only the characteristics of partnership, but also factors which promote or inhibit it (Boyle \& Brown, 2000). Often implicit or explicit is the suggestion that organizations are striving towards perfecting this organizational form, and that as

\footnotetext{
*Corresponding author. International Institute of Educational Leadership, University of Lincoln, Brayford Pool, Lincoln LN6 7TS, UK. Email: jlumby@lincoln.ac.uk
} 
experience and trust grow, partnership will overcome the barriers which exist as a legacy from previous more competitive and isolationist cultures, to the benefit of service users (Griffiths, 2000; Bennett et al., 2004). Critiques which question whether achieving mutual benefit is feasible are infrequent (Seddon et al., 2004).

This article adopts a different starting point in assuming that competition is prevalent between groups and that therefore partnership will continue to be, at least in part, an expression of and accommodation of conflict. The paper outlines the nature and purpose of 14-19 Pathfinders as reflected in national policy statements, and provides context detail about the focus of the article, a Pathfinder partnership established in 2000 involving schools and a further education college. It describes the methodology and some of the limitations in reporting due to ethical considerations. The article goes on to argue that decision-making within the partnership is at the level of the organizational group and that, therefore, theory related to the behaviour of groups, particularly those functioning in a competitive environment, is pertinent. Intergroup conflict theory (IGC) is outlined, suggesting that there are multiple impulses towards conflict between groups. The nature of conflict and a framework for analysing the discourses through which it is conducted, with anxieties about loss or gain disguised or embedded in discussion about values and/or action, are explored. One resulting effect is to create ingroup favourable and outgroup negative biases. The data, analysed through the lens of IGC, expose the conflict and bias of participants in the partnership and the effect on the development of teaching and learning. Three alternative conceptions of 'partnership' emerge.

Given the strong concerns about gain or loss, gaming theory is mined for what explanations it might offer for how people make decisions to maximize their benefit or reward and how they might work cooperatively or otherwise. The analysis of data through gaming theory does not support the Government's dependence on partnership as a means of securing cooperation and a focus on benefits for all learners. On the contrary, competitive strategies to benefit the organization rather than the learner are prevalent. National policy appears to have intensified win-lose strategies which play for the currency of young people, each of whom brings a financial reward. The limitations of both frameworks in adopting a particular lens through which to interpret human behaviour are acknowledged. Nevertheless, the article concludes that policy-making currently assumes an unfounded dependence on partnership as a cooperative win-win game in the face of evidence suggesting conflict and competitive gaming are endemic and likely to remain so.

\section{The nature and purpose of 14-19 Pathfinders}

The notion of Pathfinders was introduced in the Green Paper 14-19: extending opportunities, raising standards (DfES, 2002), as a project designed to experiment with new strategies for educating and training 14- to 19-year-old learners through partnership arrangements involving schools, further education and sixth form colleges, employers, private sector trainers and universities. Schools and colleges are the core players to date (Higham et al., 2003). Additional funding is provided to the partnership to 
pump prime structural and curriculum innovations, which it is hoped may be sustainable locally and offer helpful lessons to schools, colleges and employers in other areas.

The Green Paper indicated that Pathfinders should:

- test out a range of ideas and discover new ones;

- develop best practice in 14-19 education and training to guide the steps to, and pace of, a national roll-out;

- see how 14-19 policy will fit with other policies, identify barriers to a coherent 1419 phase and design ways to overcome them;

- show that a coherent 14-19 phase can be achieved nationally in a variety of locations with different social circumstances and different mixes of schools and colleges (Higham et al., 2004, p. 7).

The Pathfinder partnership reported in this article linked 15 secondary schools with a local further education college. Vocational courses were offered to Years 10 and 11 (14- to 16-year-olds), to be taken at the college and less often in the school or workplace. Most learners attended for a half or one day a week. A small number of learners who were experiencing severe difficulties with the school system followed individual learning plans full time at the college and on work experience.

\section{Methodology}

Providing a detailed description of the partnership and its location is problematic given the need to protect the anonymity of both organizations and individuals. Salient features which can be revealed are that the partnership covered a large area, some parts of which are sparsely populated, in some cases necessitating long distances to be travelled between organizations. The range of schools varied by size, from under 40 to just over 20015 -year-olds, and by attainment from under 12 to just under $60 \%$ attaining five or more GCSEs at $A^{\star}-C$. All but three schools had attainment of $35 \%$ or under. The Pathfinder built on a previous history of perceived partnership between the schools and college, where the college offered 'taster' courses to young people in Years 10 and 11 .

The methodology was designed to collect data to support investigation of a range of perspectives of individuals who engaged with the partnership, each with potentially different histories, needs and aims. Focus groups and semi-structured interviews were used to collect data on the experience and opinions of the partnership from young people and staff. In each school, an hour long focus group interview took place with students who had participated in the Pathfinder initiative. The sample of seven schools was purposive, selecting schools in different geographical locations and with different GCSE attainment profiles, including one special school. The groups included young people from both the years which had participated in the Pathfinder, Years 10 and 11, a range of attainment profiles and those who had become disaffected or disengaged from secondary education, indicated by their attendance record. To ensure inclusion of the perspective of those at one extreme of experience, severe 
disaffection and long-term disengagement, additionally, four young people no longer attending secondary school but following full time individual learning plans (ILP) through the Pathfinder project were individually interviewed. The groups were fairly evenly divided between young men and young women and included those on a wide range of courses. Overall 63 young people contributed their views, approximately $15 \%$ of all those participating.

A range of staff in the schools/college and support services were also interviewed. The role titles of those interviewed within each school varied, but the range included the most senior member of staff with specific responsibility for the development of teaching and learning and the Heads of Years 10 and 11. Representatives of Connexions, LEA Pupil Services and School Improvement were also interviewed. In the college, the Vice-Principal, the 14-19 Team Manager and Coordinator, and a sample of tutors and those supporting the teaching and learning of 14- to 19-year-olds were interviewed. Overall, the views of 23 staff involved in supporting young people through the partnership were collected, reflecting a range of perspectives from strategic to operational.

The data from 63 young people and 23 adults are a relatively small number, and no claim is made that a complete picture of this partnership has been assembled. The data are being mined for analysis from a variety of perspectives. For the purposes of this article, the views of staff are particularly critical in terms of decisions about how the schools and college conceived and enacted partnership. Further articles will explore in more depth the experience of learners as individuals and groups relating to and experiencing the partnership. The data are used here to allow an exploration of the perceptions about the nature of one partnership from a number of perspectives, sufficient to explore how partnership appears to be conceived and enacted.

\section{Analysing 'partnership'}

While Government policy may lack specificity and clarity in defining the nature and aims of partnership, the general thrust is apparent. It is seen as a means of addressing particularly the "“wicked issues" (Stewart, 1996) facing Government-issues that can only be tackled by bringing together the resources of a range of different providers and interest groups' (Lowndes \& Skelcher, 1998, p. 3). 14-19 education and training is one such issue. Much policy and public rhetoric appears to disingenuously ignore the considerable research suggesting the entrenched and destructive nature of competition between educational organizations (Glatter et al., 1997; Kennedy, 1997; Lumby, 1998). Instead it assumes that schools and colleges will wish to work together to achieve educational aims and can do so productively to the benefit of learners as a whole. It is organizations rather than individuals who are assumed to be partners. As it is therefore at the level of groups that interaction is conceived, and the intention is for groups to move from previously competitive to more collaborative strategies, both intergroup conflict (IGC) and gaming theories may offer useful frameworks for exploring the data. 
A group is defined as 'a delineated social unit with properties which can be measured and with consequences for the behaviour of its members' (Sherif \& Sherif, 1953, p. 9). Though each organization will comprise individuals who have differing personal values, beliefs and predilections for action, the school or college will exhibit 'a set of norms regulating members in pursuing goals, in relationships with one another and with outgroups' (Sherif \& Sherif, 1953, p. 9). The norms shape and impel the beliefs and actions of individuals into one discernible direction, that of the group. Therefore, although each school and college could be analysed through the behaviour of individuals and of multiple groupings, this article focuses on organizations as discrete groups, as it is as a group that strategic decisions about engagement and aims are made in relation to the partnership.

The theoretical frameworks offered by both IGC and gaming theory appear to be founded on a view of human behaviour as fundamentally rational, that is players make choices by a logical calculation of their best tactic to maximize benefit. However, both theoretical areas are complex and rich, and share a degree of ambivalence in their orientation to rationality, allowing for irrational choice. For example, IGC studies have noted group pursuit of a larger share of the total good available to the point of destroying the good for all (Hardin, 1995). Gaming theory acknowledges a tactic of revenge which causes detriment to another but also to oneself (Sapolsky, 2002). However, the main thrust of both frameworks is to unravel the way groups behave primarily to serve their own interests. The existence of altruism as action to benefit only others is largely denied. The use of this theoretical framework therefore obviously introduces limitations in the way human behaviour is viewed and analysed. Nevertheless, it offers the chance to step outside anodyne policy assumptions about altruism in education partnerships and the expected reduction of competition, and to view the data through an entirely different lens. The article will interpret the data in terms of the relations between groups and the intended beneficiaries of group action.

\section{Intergroup conflict theory}

Conflict can be defined as:

... a situation in which interdependent people express (manifest or latent) differences in satisfying their individual needs and interests, and they experience interference from each other in accomplishing these goals. (Donohue \& Kolt, 1992, p. 4)

Conflict between groups can arise from 'real' needs such as competition for scarce resources, but ethnographic studies have indicated that the interests of groups often exceed achieving merely sufficient material resource. As an example of the ubiquitousness of such wider aims, one might consider those of groups which apparently have little in common with educational organizations. For example, the goals of a Tlingit clan, a group of Alaskan Native-Americans were:

(1) to secure basic resources for survival;

(2) to accumulate material wealth for security;

(3) to increase social standing vis-a-vis other clans; 
(4) to promote privilege and prestige;

(5) to establish alliances with other autonomous clans; and

(6) to expand their resource base, wealth, and prestige sphere (Tollefson, 1995, p. 3).

Research amongst other groups has discovered the same imperatives for securing not only physical resources but also social status (Jackson, 1993) and social domination (Alexander \& Levin, 1998). Groups may not wish just for enough, but to have more than others and to accrue status. Such aims resonate with micropolitical analyses of schools and colleges (Ball, 1987; Bowe et al., 1994; Lumby, 2001). In the context of resource constraint in the public sector, and education specifically, it might therefore be reasonable to hypothesize that schools and colleges may be conflictual groups as they compete for scarce funding and also strive to raise their status. The quasi market established by Government policy through a variety of means is strengthening conflictual postures. Learners are able to make a choice between schools and colleges, (at least in theory though the degree to which such choice exists has been seriously questioned (Ball, 2003; Lumby \& Wilson, 2003)). League tables allow potential 'customers' to compare the performance of institutions. Funding methodologies based on learner numbers reward those who capture customers. In such a context, it appears highly likely that whatever the rhetoric of Government about collaboration and partnership, the attainment of the goals of one organization will interfere with the attainment of the goals of one or more others.

However, even where resources are not in short supply, conflict may still arise. 'The mere act of categorizing individuals into groups' (Alexander \& Levin, 1998, p. 630) can lead to conflict. It would seem that conflict between groups may exist whatever the context and in contradiction to theory from a number of perspectives, anthropological, sociological, psychological (Jackson, 1993), and to realistic group theory, which posits shortage of resources as the primary driver of conflict (Alexander \& Levin, 1998). Ochbuki and Suzuki (2003) draw on the work of Druckman (1994) and Harink et al. (2000) to suggest three kinds of conflict issues:

- Gain/loss issues: the acquisition or loss of resource.

- Correct/incorrect issues: differences of opinion on how a task should be performed.

- Right/wrong issues: difference of opinion on underlying values (adapted from Ochbuki \& Suzuki, 2003, p. 63).

This model resonates with the idea that conflict may be created by factors other than competition for resources. However, it may be difficult to disentangle disagreements on the how and why of action from an underlying impetus to gain resource. In other words, apparent disagreement about actions and values may be a convenient disguise or vehicle for competing for resources. IGC suggests such is the case.

This relates to one effect of intergroup conflict, which is a favourable bias towards the ingroup and a negative bias towards outgroups. Rather than logical and objective assessment of the validity of another's opinion, one will tend to approve of those of one's own group and view negatively those of another. Perceptions of correct/incorrect 
and right/wrong issues are coloured by loyalty to one's own group and hostility to other groups. Outgroup hostility may be reduced if superordinate goals are mutually desired and can only be achieved by collaboration (Jackson, 1993). The literature of education partnership stresses the same strategy, the importance of agreed common goals (Boyle \& Brown, 2000). However, IGC theory suggests that such goals must be sustained for a considerable period, or they will have no effect. A short-term alliance to achieve common aims is unlikely to impact on long-term conflict (Jackson, 1993). This brief consideration of intergroup conflict theory suggests that the data from the 14-19 partnership could be analysed to explore how far there is competition for resource, how far ingroup favourable and outgroup unfavourable bias remains, despite adopting a partnership, and how far superordinate goals have been established and their impact on the degree of competition.

\section{Conflict within the partnership}

On one level, much of the data indicates an absence of conflict and considerable success. The majority of learners were positive about the partnership. Many staff also spoke in praise: 'It is extremely good. It is one of the best examples of partnership that I have seen in this county'. (LEA Support Service).

The achievement and retention data and the views of the learners themselves evidenced the increase in opportunities and success afforded by the partnership. Attendance of learners on Pathfinder programmes was consistently higher than at school, by an average of $14 \%$ over three years. In the third year of the partnership, the success rate, that is the percentage achieving the qualification intended, was over $80 \%$. For some learners, the programme had been a critical lifeline back into education where other initiatives run by a school or by the LEA had failed.

However, beneath this positive surface, a number of negatives emerged. Specifically a substantial minority of young people were dissatisfied. For some young people, the perception that one needed to be 'thick' or 'troublesome' or both at school in order to qualify for attendance at college led to a loss of self-esteem. In one school, the focus group perceived that those who were 'too brainy' were not allowed to participate. 'People who go to college are dumbos'. Additionally, some learners and school staff felt the treatment of young people at the college was on occasion less than respectful, and did not take account of the very vulnerable nature of some of the learners. The root of dissatisfaction appeared to be a difference in the goals of participating education groups.

\section{Superordinate goals}

The purpose of the partnership was signalled by staff respondents as improving the learning experience and outcomes for 14-19 learners. At this general level there was agreement, but the data indicate the presence of underlying gain/loss issues, reflecting different emphases amongst three stakeholder groups but expressed through differences in correct/incorrect, right/wrong issues. Although there was no neat absolute 
division, college staff tended to emphasize the relationship of the partnership activity to Government policy, persuading young people of the value of lifelong learning, thereby raising participation rates. School staff tended to stress raising achievement and meeting the needs of young people for whom the National Curriculum and/or the school environment were not appropriate. The differing priorities of the schools and college groups are apparent. For college staff, hooking learners into their vocational subject so that they would enrol at the college at 16 years and perhaps return to training throughout their life was important. For schools, both improving results at 16 years and finding a solution to perceived challenging learners was critical. In both cases, while the aim is couched in politically correct rhetoric linked to national policy and teaching and learning issues, the differences reflect a gain/loss agenda. Schools wanted to solve the 'problem' of challenging pupils and potentially raise their attainment and thereby their position in the league tables. The college wished to increase its market share both pre- and post- 16 .

There were also differences in beliefs about the target group of the partnership, who it was designed to serve, and the values demonstrated in offering a choice to pupils or not, i.e., right/wrong issues. The range of practice articulated by respondents in the project included:

- Learners make the choice to participate in Pathfinder programmes or not, with support and guidance.

- Schools select learners to participate, identifying those who are challenging academically or in their behaviour.

- Schools select learners on the basis of benefit and fit, including potentially high academic achievers.

- Schools send the entire year.

Different aims and value bases underlie such choices. The different positions within the partnership were:

1. The programme commenced by catering for lower academic attainers and has remained so. This is regrettable, but has not changed.

2. The programme commenced by catering for lower academic attainers but it has changed and continues to do so and is now catering for a wider profile.

3. The programme is more suitable for those with low academic attainment and behavioural/confidence problems and should continue to target such learners.

The position of respondents appeared to reflect their interests. For example, a Deputy in a school which was considering developing vocational provision in house rather than paying for learners to go to the college adopted 'Position 2':

We take a lot of factors into account in choosing learners. They are not necessarily the weakest academic students. Some are capable of achieving A-C. I rely on the Heads of Year as they know the learners. There are flexible criteria for selection. If we think a child would benefit, it doesn't matter if they are able to get A-C ... we just look at them as individuals. 
Such a stance would allow the school to offer vocational provision across a range of learners and not just limit them to the selection of, and payment for, the exporting of certain students to college. Position 3 was expressed by a member of the support service: 'What Pathfinder actually offers is provision for meeting the needs of Level 1 students that cannot be met in school'.

The data do not evidence absolute and consistent connections between position held and personal interest, reflecting gain/loss issues expressed in right/wrong values debates. However it does suggest such a connection in many cases, if only because the opinion of some, those adopting Positions 1 and 3, is not supported by the numeric evidence. In fact, the profile of participants had changed over time and now included more learners with higher academic attainment. There had been a decline in the percentage of those commencing on entry level programmes, with prior attainment of SATS $1-2$, from $100 \%$ of the first cohort in 1999 to only $12.5 \%$ by $2003-2004$. Level 2 programme entrants with prior attainment at SATs Level 3-4 had grown steadily, from $0 \%$ to $60 \%$ over five years. From 2001-2004 approximately a quarter of entrants had prior attainment at SATs Level 5+. The figures support the view of those staff who felt the programme was catering mainly for learners at entry to Level 2, with SATs at Level 4 or below on enrolment, but more than a quarter of participating learners are now starting with higher levels of attainment. Nevertheless, staff views made clear that some schools selected learners with a view to the school's best interests rather than those of the individual learner. In one school, the issue was improving GCSE results, so able students were excluded (the 'too brainy'): 'Because of Government targets we need able students to meet the target of achievement of A-C GCSEs. We have to meet the school targets as well as student needs' (Deputy Head).

In another school, the concern was that allowing too many learners to participate in college programmes would deplete sets for subjects in school:

If sending them to do what they want at the college means that we would lose some subjects in school, then that's something we would have to look to do. We need a year to run that through because it would have an impact on staffing. (Deputy Head)

Some schools therefore wanted to send to the college selected young people who would be unlikely to contribute to their own results and therefore status, and who might furthermore cause difficulties by their challenging behaviour. College staff wished for motivated students who would conform to behaviour rules and might go on post- 16 to train in the vocational area they had experienced pre-16 at college. The mismatch 'is a sort of barrier between school and college' (Head of Year).

While the staff interview evidence reflects the perspective of individuals, there was a degree of congruence between the views of members in each group suggesting an overall group orientation resting on the perceived interests of the institution.

\section{A model of partnership}

Overall, partnership was seen in very different ways by respondents, reflecting how far they subscribed to superordinate goals or saw their group goals as the priority. 
There are three concepts of partnership indicated by staff in both schools and the college:

- Partnership as complement.

- Partnership as synergy.

- Partnership as trust.

Partnership as complement was reflected in the comments of staff indicating that the aim was for the college to provide what the schools could not. The programme is 'a convenience'. One school Head of Year suggested, 'The relationship with the college is not a partnership; it is a bolt on'. The reasons for this opinion were expressed as both lack of knowledge of what was happening to the young people when they were in college, and lack of confidence in the college's ability to cater for the needs of 14to 16-year-olds. Therefore, it was argued, neither the staff nor the young people had a sense of wholeness and satisfaction in their experience. The conflict was expressed as both a correct/incorrect issue-the best location for the education of 14- to 16year-olds, and a right/wrong issue-the values of college staff in their behaviour to young people. The only reason for the Partnership was to access the college's resources, specifically facilities, which the school lacked. The school is committed to doing as much in house as it can and using the college's resources to supplement what the school cannot offer in order to meet the school's goals.

In this perspective, each school is pursuing its own individual path in its own way and the Partnership is relevant only insofar as it supports the achievement of the school's goals. As one school Deputy explicitly acknowledged, 'The vocational courses results have helped us achieve our targets'. The schools and college are held together only by the convenience of 14- to 19-year-olds accessing a wider range of courses. As a result of the weak adherence to superordinate goals, conflict expressed through competition was strong. Several schools would exit from the Partnership if by doing so they could gain. In the case of two schools, this was under active consideration. Others were considering reducing their engagement with the college by replicating some of the courses offered by the college in-house. Though the reasons were often couched as correct/incorrect issues, such as the distance learners had to travel, the lack of choice to remain in school, the benefit of the pastoral care of schools, resource issues were intertwined in the reasoning. Gain/loss was inextricably connected with beliefs about correct/incorrect actions to meet learners' needs.

Partnership as synergy was reflected in the belief of some staff that the partnership went beyond just bolting on additional courses; that by working together courses could be created or made viable that would not otherwise have been the case. By working together the partnership could extend options beyond those currently available merely by adding together the existing curricula of the schools and college. In this case, the groups saw adherence to a superordinate goal as potentially of mutual benefit, but there remained the possibility to disengage. One school Deputy Head felt, 'I would like to work with other schools to make up groups and extend options'. Here there is recognition that actively working together might create new possibilities, rather than simply allowing access to existing ones. 
Partnership as trust was suggested in the comments of staff who saw the alignment of values as fundamental, leading to an alignment of direction, and its enactment through common systems, for example of quality assurance and behaviour management. In this conception of partnership, it is not a question of adding disparate elements together but of creating one coherent whole based on common values and aims to achieve a greater good for local education and training. In this case, superordinate goals were seen as long-term and disengagement unlikely. One school Deputy Head pondered of other schools, 'If we are all in on this, why do we need different systems?'. This Deputy is aiming towards agreement on correct/incorrect issues at least, apparently setting aside gain/loss conflict. In similar vein, one college member of staff reflected on earlier disagreements but now felt, 'The competitive environment does now influence very little. We have a true partnership and share problems and issues as we go along. We have a partnership of trust'.

However, those in all three categories, even those in the third category of trust, expressed adherence to action to maintain or increase their resources and shared concerns about funding being cut off at the end of the project. Also, perceptions of the partnership were not always consistent. The intrusion of concern about resources meant commitment to synergy or to trust existed alongside perceptions of the partnership as complement only. For example, one school Deputy indicates a view of partnership both as complement and as synergy in two sequential sentences:

There is a lot of potential for working with the college, perhaps a number of schools putting learners together to make up group sizes (synergy). It would be much more cost effective for us to work with the college in the school, than to bring learners to the college (complement). (Our additions in italics)

The importance of additional resource as a motivation for partnership and the fragility of agreement if it might lead to erosion of resource was apparent in much of the data. The sustainability of the superordinate goals was therefore in question even for those who were strongly committed to the partnership.

\section{Ingroup and outgroup attitudes}

Much of the normative Government literature on partnerships stresses the advantage of bringing together the various strengths of different types of organization for the benefit of learners and assumes the commitment of education organizations to working together in harmony to this end. IGC theory suggests a rather different scenario. Rather than individuals and groups valuing the difference of other groups, those who have derived power from the existing situation, or who are dominant in other ways, by means of their position or characteristics (for example, gender or ethnicity) are likely to adopt a negative view of perceived subordinate groups, reflected in stereotypical assessments of their characteristics (Alexander \& Levin, 1998). Equally, those who are under stress, for example, from low levels of resource or status, may have a negative view of their competitors. Shifts in the perceptions of others will not rest on rational assessments of their position and values. Rather such shifts are a function of 
the degree of perceived competition and status wars (Jackson, 1993). The positive opinion of the ingroup may strengthen, and the group's norms are not viewed as relative, but rather as right in an absolute sense. The fact that the norms are reinforced by their alignment with self-interest passes unnoticed (Hardin, 1995). Right/wrong issues become the acceptable face of gain/loss anxieties. Using IGC one might therefore predict that schools in competition with one or more colleges, and particularly those with low attainment levels and therefore low status, might see their own attitudes and practice in a positive light as appropriate for young people, and be dismissive of the practice of the college. The latter equally might denigrate the practice of schools and see what they offer as preferable. Such stereotyping of outgroups has been noted in partnerships. For example, Lowndes and Skelcher (1998) found that in public private partnerships, private sector participants believed public sector workers to be left wing and difficult to work with. The latter felt business 'partners' were attempting to use public sector schemes cynically to forward their business interests. Both were hostile to local authority attitudes.

Such intergroup hostile attitudes were evident in our data. For example, one college member of staff was extremely positive about what the college offered young people and negative about schools in general: 'At college you are out of uniform. You are treated as an adult. You are treated with respect'.

This respondent is indicating that the college is correct (in allowing young people to wear their own clothes) and right (in the underlying values of equity and respect). He described the incredulity of young people visiting the college for the first time and unable to believe that they could use the exciting equipment on offer, an emphasis on the greater resource level of the college, a mark of status. He believed both students and college staff were enormously positive about their experience. In contrast schools were depicted negatively:

There are things in a school that you can never get past whether you are teaching sociology or motor vehicle maintenance. Even with motor vehicle they would still want you to come in a uniform with your shirt tucked in.

The symbolic action of asking for a shirt to be tucked in during motor mechanics implies schools are both incorrect in their procedures and also wrong, in inappropriately controlling and therefore lacking respect for young people. These beliefs were not upheld in the data, where a sizable minority of young people thought the college cold, mucky, and the staff sometimes disrespectful, and some learners were positive about their school. This respondent is recasting the experience and opinion of some to a universal truth. Both college and school are stereotyped, one positively and the other negatively.

School staff equally sometimes held negative views of the college. One school Deputy felt that the way college staff treated learners was unsatisfactory: 'One student was told [in college] he was "a waste of space". There are issues about how politically correct the tutors are'.

Another member of staff in the same school was 'not overly enamoured with what the college provides for the learners'. This school was of perceived low status and 
struggling to raise its results and prestige. The 'bolt on' view of partnership was prevalent and it was considering leaving the partnership to go it alone. This being the situation, IGC theory would suggest the likelihood of deepening negative attitudes towards the outgroup and this indeed appeared to be the case. The fact that such views are subjective is emphasized by the contrast of the view of this school with some other schools where the belief was that the college was excellent in what it provided. The data suggest, not surprisingly, that learners held differing opinions on the approach to and quality of learning on offer in both the schools and college. However, each school or college tended to set aside such variety and depict each other either in wholly positive or negative terms. The differences in opinion and commitment are striking and appear to support the notion that views of outgroups will be strongly influenced by the degree to which that outgroup is seen as inferior/superior and how far the superordinate goals are in fact working for the group. In the case of the negative school, academic results had not been particularly improved by the partnership and the attitude to the college outgroup was hostile. In a second school, despite there having been learning and teaching problems, such that 'We send staff with the children to support them. Our teachers feel they need to be there to drive forward progress', academic results had improved substantially and the assessment of the college outgroup was extremely positive. The difference is not the presence or absence of quality problems, but the degree of weight this was given in the overall view of the college as an outgroup. The connection suggested by IGC, that groups which provide benefit are seen favourably and those which do not are treated with hostility, is apparent.

\section{Partnership and gaming}

Gaming theory, a branch of mathematics originally developed in relation to economics, has been annexed by biologists, psychologists and sociologists, amongst others, to provide insights into human behaviour (Gantt \& Reber, 1999). The theory assumes that players are able to make choices about what actions will accrue the greatest rewards or advantage in any situation, and will generally make rational decisions. However, the choice process is complicated by judgements about the effect of how others will act, both immediately and in the future, hence 'the game'. Thus players will consider what their reward or advantage might be, if gaining it will rob other players of the reward, or whether a different cooperative strategy will offer the same or greater gain to all players. They will also consider the effect of how others choose to act, and based on this calculation, devise their own strategy. The insights resulting from experiments on how players choose offer rich and challenging insights into the behaviour of human beings. A particularly pertinent strategic choice explored by the theory is the decision to cooperate or to compete to gain advantage. Saplosky (2002, p. 1) argues that all 'social animals ... have often evolved strategies for deciding when to cooperate and when to cheat', raising questions about human capacity for and use of altruism and trust. In contradiction to the disingenuous assumptions of public policy on partnership, gaming theory suggests that acting to gain advantage by disadvantaging another is as much an option as cooperating for advantage. 
One finding which is relevant is that individuals may give up advantage for themselves if by their actions they can benefit a group (Saplosky, 2002). Such apparent altruism is generally enacted to benefit a group which has some strong tie, whether genetic relatedness, or a sense of relatedness. The sense of relatedness may be experienced as IGC suggests, not as a result of longstanding history, but merely by being categorized as a group. Gaming theory therefore suggests that individuals in a school or group may act unselfishly to gain advantage for their organization. However, the question for partnerships is whether being categorized into a group called a 'partnership' gives a sufficient sense of relatedness to encourage individual subgroups, the schools or college, to act in the best interests of all.

The assumption that games are played by humans and that strategies are adopted in order to win advantage over others is clearly relevant to the intergroup conflict the article has explored and to the context in which education, and conceptions of partnership, are evolving. The theory as expressed mathematically is highly complex and cannot be fully described in this article, but the major strands of how far players are acting to gain advantage through cooperation, and with what reward in mind is clearly relevant.

Much of the literature depicts the era post the Education Reform Act (HMG, 1988 ) as a period when zero sum games were played by education organizations; that is, there was a competitive environment in which players perceived if one organization won, another would lose (Glatter et al., 1997). As funding was tightly linked to numbers enrolled, if students went to one school, then enrolment at another, and therefore its resource, would reduce. If a learner opted for college, the school would be the loser and vice versa. In a zero sum game, the total winnings of one player equal the total loss of another. In this sense the learner was the unit of currency for which education organizations played, and like poker chips, was non-divisible, the unit of gain/loss. Of course this absolute in the pure mathematical sense of gain=loss is rarely the case in practice, but for the purposes of analysis, the competitive environment at its height can be seen as one where the fear of a zero sum game shaped the attitudes and actions of educators (Lumby, 1998).

The player in this context is the organization and consequently, gains and losses are seen primarily at the organizational level, rather than that of the individual learner. There is ample evidence that despite the rhetoric of putting learners first, the organization's interests take precedence as it is the player of the competitive game. For example, there is considerable evidence that young people are not given access to information and guidance which might support enrolment in another organization even when this might be in their best interests (Schagen et al., 1996; Lumby, 1998). Selection of entrants may be manipulated to ensure the best league table position and therefore status, excluding young people whose needs may cause the organization too much loss, however defined (Edwards \& Whitty, 1997; Lumby, 2001). The data analysed earlier in this article suggest that young people's interests can be seen as less compelling than those of the organization. Schools and colleges are playing non-cooperative games, selecting strategies based within a win-lose framework. 
The rhetoric of partnership demands that education organizations move from a zero sum game to a non-zero sum game. The latter is one where rather than winnings equalling losses, payouts are differential according to strategy, and where therefore there may be more than one winner. Conceivably, all players can be winners. Non-zero sum games can be played cooperatively, players negotiating to get the best deal for all, or non-cooperatively where players compete to get the best deal they can for themselves.

Glatter (2003) and Hall (1999) have pointed out that some schools and colleges began to move towards cooperative games, based on non-zero sum assumptions even before the rhetoric of partnership was highly developed. Such cooperation is dependant on the selection of a strategy which is best for all the groups involved, the coalition. However, as McCain (1999) points out, organizations are at liberty to negotiate for the biggest bribe they can achieve for agreeing to such a strategy. The move to cooperation and negotiation is an alternative strategy chosen to secure gains for the organization. It is not a move from competing. The game is still in operation. Rather it is commitment to a different set of rules of engagement which the organization judges may be more fruitful. 'Allocation' is the reward or payoff. Allocation is efficient if no one can be made better off without making someone else worse off, and inefficient if at least one player can do better while no other is worse off.

What insights might such theory offer if applied to our data? Firstly, what evidence is there that players are concerned to choose the best option for all, rather than just the best strategy for themselves? There is no evidence that suggests that any of the partnership organizations were thinking of the best strategy to meet the needs or wants of all local learners. Even in those schools which opted to send a whole year, or to allow young people to make the choice to participate or not, and who therefore did not exclude young people in the school's interests, the aim was primarily to meet the needs of the school through meeting the needs of their own learners.

Nor is there evidence that organizations were seeking the best payoff for all partners. For example, one school valued the partnership as a way of raising its achievement level and exceeding targets as part of a strategy to exit special measures. Another was happy for their young people to have access to vocational tasters, but was actively considering establishing such courses as a post-16 option itself, in order not to have to send young people to the college. In both cases, the payoff was not conceived as a payoff to the coalition, but to the school as an individual player. Equally, the college saw the partnership as a means of growing its funding and provisions. As one Head of Department saw it:

It has allowed me to take on more full time staff. Two hundred students or more are accessing our programmes. It has allowed me to turn a series of part time staff into full time staff and to develop a team. Working with 14 -year-olds will help staff working with 16-year-olds, as they know where they are starting. It makes them better FE teachers. However, the use of facilities is having a negative impact on full time courses, so we are looking more at delivering off site.

The future, even one where cooperation with schools was closer (college staff delivering offsite by teaching in the schools), was assessed in terms of its impact on the college, not in terms of its benefit to all learners. 
In this partnership, the data suggest that the allocation is inefficient (McCain, 1999). Given that there was a cost involved in sending young people to the college, if a school could offer an equivalent provision in house, they would gain financially. The college would not necessarily be worse off, as demand exceeded capacity. Several schools, having seen the success of the partnership, were considering offering vocational education and training in house by expanding their own provision, perhaps using college staff, or perhaps their own. In other words they were considering reshaping partnership arrangements in order to accrue greater benefits for their organization. In fact, for many of the young people, a major benefit of the experience was learning in a college environment, which some felt a school could not reproduce. Therefore, it is likely that reshaping the partnership activities, with more vocational courses undertaken in schools instead of in the college, would benefit the coalition considerably, but at a cost to young people of a dilution of the experience.

One might argue that given that demand for college places was outstripping supply, there was no alternative, and schools were simply compromising in the best way possible to achieve some improvement in young people's experience. However, the point of the data relevant to our understanding of partnership, is the orientation of partners. They were not considering a full range of alternative ways of meeting learners' needs. Rather they were aiming to find an allocation which benefited them as an individual organization first and the partnership second.

In an education context, allocation may be inefficient within partnerships. One or more partners could be better off without necessarily disadvantaging others. Alternatively, if the allocation is efficient and a gain for one is likely to mean a detriment to another, if partners are playing non-cooperatively, they will not care that this is the case, and may strive for individual gain nevertheless. The ideal type partnership where allocation is efficient, and no partner will act to disadvantage other members seems rather remote from what empirical evidence to date suggests about educational partnerships. The evidence suggests that in this partnership, cooperative non-zero sum gaming was at best very fragile and at worst illusory. Partners were not concerned with the best strategy for all players, but the best strategy for themselves. It was a noncooperative, non-zero sum game.

\section{Partnership, conflict and games}

Drawing together the threads of the analysis, the rhetoric of Government clearly indicates a belief that schools and colleges will move to a form of organization, partnership, where organizations can operate in the best interests of learners in a defined geographical area (DfES, 2002). Such ambitions run counter to what we know of groups and their interaction, and the gaming which is endemic in a situation where there can be gains and losses.

Groups do not act rationally. Even where there is no apparent cause for dispute, merely forming people into groups may lead to negative views of other groups (Alexander \& Levin, 1998). Gaming is inherent even in lower forms of life, let alone 
human groups. 'Even social bacteria have evolved optimal strategies for stabbing each other in the back' (Saplosky, 2002, p. 1). The partnership explored in this article was in many ways admirable. It had offered new opportunities and success to many young people and was seen positively by the majority of those involved. This was despite the absence of two characteristics suggested by IGC and gaming theory as likely to reduce conflict, adherence to superordinate goals, and sustained contact between the groups. However the overall impression left by the data is that the initial success was a firework burst, a display of cooperation fuelled by additional Government funding, which in the longer-term would settle more deeply into the conflict and gaming explored earlier.

Working groups such as the Tomlinson-led review of 14-19 education (Working Group on 14-19 Reform, 2004) can suggest policy to meet the interests of learners, assuming a degree of partnership to such ends. Our evidence suggests that the best interests of the organization are likely to take precedence, and that hostility to other groups, bolstered by stereotypical negative views, will persist. This is not to suggest the educators do not care about learners. Many of the respondents cared deeply about the learners in their organization, but there was little sense that they cared about learners in a wider sense, beyond the boundaries of their own organizations, just as parents care about their child, rather than children in the generality. Rather than assuming that rationality and professionalism will prevail and schools and colleges will act in the interests of all local learners, policy-makers would do well to assume that competition, conflict and gaming are likely to continue. Much analysis to date has suggested that Government polices such as marketization and funding regimes have been responsible for such attitudes (Glatter et al., 1997; Kenendy, 1997; Felstead \& Unwin, 2001; West \& Pennel, 2000). Sociobiological, social constructionist and political analyses suggest that such critiques give too little attention to the more fundamental and inherent compulsion of groups towards self defence and self aggrandizement.

A fruitful area for deeper consideration by policy-makers may be the factors which inhibit conflict and create the conditions for cooperative gaming. Firstly, superordinate goals must be sustained. At the moment policy changes so rapidly, there is no time to build adherence to superordinate goals. Secondly, building knowledge of other players, sustained contact, is needed to create confidence in predicting the behaviour of other players. The latter is suggested by gaming theory as a prerequisite for players to begin to create a model of the strategies of other players, and therefore confidence in predicting how they will behave. If cooperative strategies can be predicted, players may be prepared to altruistically suffer some immediate loss in order to gain longerterm benefit (Humphrey, 1997). Finally, funding currently still constitutes the learner as a zero sum currency. The gain or loss of a learner matters and so is a pressure towards competitive rather than cooperative gaming. If Government genuinely sees the future as partnerships, they must pay as much attention to creating the conditions for successful partnership as to the rhetoric of the gains to be offered by its adoption. Even then, competition and conflict will not disappear, but there may be a fighting chance for learners to get a look in. 


\section{Notes on contributors}

Jacky Lumby is Professor of Educational Leadership and Director of Research at the International Institute for Educational Leadership, the University of Lincoln. Her research interests are in policy and leadership, particularly in 14-19 and post-compulsory education.

Marlene Morrison is Reader in Educational Leadership and Learning at the International Institute for Education Leadership, University of Lincoln, where she leads the professional doctorate programme. Her research reflects methodological and substantive interests in lifelong education, and leadership for social justice and inclusion.

\section{References}

Alexander, M. G. \& Levin, S. (1998) Theoretical, empirical and practical approaches to intergroup conflict, Fournal of Social Issues, 54(4), 629-639.

Ball, S. (1987) The micro-politics of the school (London, Routledge).

Ball, S. (2003) Class strategies and the education market (London, RoutledgeFalmer).

Bennett, N., Harvey, J. \& Anderson, L. (2004) Control, autonomy and partnership in local education, Educational Management Administration and Leadership, 32(2), 217-235.

Bowe, R., Ball, S. \& Gewirtz, S. (1994) Parental choice, consumption and social theory: the operation of micro markets in education, British fournal of Educational Studies, 42(1), $38-52$.

Boyle, B. \& Brown, M. (2000) Holy grail or poisoned chalice? A case study of partnership collaboration between a university school of education and a private sector education company, Westminster Studies, 23(1), 31-40.

DfES (2002) 14-19: extending opportunities and raising standards: summary document (London, The Stationery Office).

Donohue W. A. \& Kolt, R. (1992) Managing interpersonal conflict (Newbury Park, Sage).

Druckman, D. (1994) Determinants of compromising behaviour in negotiation, fournal of Conflict Resolution, 38(3), 507-556.

Edwards, T. \& Whitty, G. (1997) Specialisation and selection in secondary education, Oxford Review of Education, 23(1), 5-15.

Felstead, A. \& Unwin, L. (2001) Funding post compulsory education and training: a retrospective analysis of the TEC and FEFC systems and their impact on skills, fournal of Education $\mathcal{E}$ Work, 14(1), 91-111.

Furlong, J., Whitty, G., Miles, S., Whiting, C., Barton, L. \& Barrett, L. (1996) Re-defining partnership: revolution or reform of initial teachers education?, fournal of Education for Teaching, 22(1), 1-18. Available online at: http://search.epnet.com/direct.asp?an=9607103434\&db=afh (accessed 26 May 2004).

Gantt, E. \& Reber, J. (1999) Sociobiological and social constructionist accounts of altruism: a phenomenological critique, Fournal of Phenomenological Psychology, 30(2). Available online at: http://search.epnet.com/direct.asp?an=2930785\&db=afh (accessed 23 August 2004).

Glatter, R. (2003) Collaboration, collaboration, collaboration - the origins and implications of a policy, Management in Education, 17(5), 16-20.

Glatter, R., Woods, P. \& Bagley, C. (1997) Diversity, differentiation and hierarchy: school choice and parental preference, in: R. Glatter, P. Woods \& C. Bagley (Eds) Choice and diversity in schooling: perspectives and prospects (London, Routledge).

Griffiths, M. (2000) Collaboration and partnership in question: knowledge, politics and practice, Fournal of Education Policy, 15(4), 383-395. 
Hall, V. (1999) Partnerships, alliances and competition: defining the field, in: J. Lumby \& N. Foskett (Eds) Managing external relations in schools and colleges (London, Paul Chapman).

Hardin, R. (1995) Contested community, Society, 32(5), 1-7. Available online at: http:// search.epnet.com/direct.asp?an $=9507106193 \& \mathrm{db}=\mathrm{afh}$ (accessed 16 August 2004).

Harinck, F., De Dreu, C. \& Vianen, A. (2000) The impact of conflict issues on fixed-pie perceptions, problem-solving and integrative outcomes in negotiation, Organizational Behaviour $\mathcal{E}$ Human Decision Processes, 81(2), 329-358.

Her Majesty's Government (1988) Education Reform Act (London, The Stationery Office).

Higham, J., Haynes, G., Wragg, C. \& Yeomans, D. (2004) 14-19 Pathfinders: an evaluation of the first year. Summary. Available online at: www.dfes.gov.uk/14-19/dsp_evaluation (accessed 26 May 2004).

Humphrey, N. (1997) Varieties of altruism and the common ground between them, Social Research, 64(2), 1-6.

Jackson, J. (1993) Realistic group conflict theory: a review and evaluation of the theoretical and empirical literature, Psychological Record, 43(3), 1-15. Available online at: http:// search.epnet.com/direct.asp?an=9312270962\&db=afh (accessed 16 August 2004).

Kennedy, H. (1997) Learning works: widening participation in further education (Coventry, FEFC).

McCain, R. A. (1999) Strategy and conflict: an introductory sketch of game theory (Rose Valley, Pa). Available online at: http://william-king.www.drexel.edu/top/eco/game/game.html (accessed 14 August 2004).

Lowndes, V. \& Skelcher, C. (1998) The dynamics of multi-organizational partnerships: an analysis of changing modes of governance, Public Administration, 76(2), 1-18. Available online at: http://search.epnet.com/dierct.asp?an $=1034000 \& \mathrm{db}=$ buh (accessed 18 August 2004).

Lumby, J. (1998) Restraining the further education market: closing Pandora's box, Education $\mathcal{E}$ Training, 40(2), 57-62.

Lumby, J. (2001) Managing further education colleges: learning enterprise (London, Paul Chapman).

Lumby, J. \& Wilson, M. (2003) Developing 14-19 education: meeting needs and improving choice, fournal of Education Policy, 5, 533-550.

Ochbuki, K. \& Suzuki, M. (2003) Three dimensions of conflict issues and their effects on resolution strategies in organizational settings, International fournal of Conflict Management, 14(1), 61-73.

Sapolsky, R. (2002) Cheaters and chumps: game theorists offer a surprising insight into the evolution of fair play - findings, Natural History, June. Available online at: www.findarticles.com/p/ articles/mi_m1134/is_5_111/ai_86684497 (accessed 22 August 2004).

Schagen, S., Johnson, F. \& Simkin, C. (1996) Sixth form options: post-compulsory education in maintained schools (Slough, NFER).

Seddon, T., Billett, S. \& Clemans, A. (2004) Politics of social partnerships: a framework for theorizing, fournal of Education Policy, 19(2), 123-143.

Sherif, M. \& Sherif, C. (1953) Groups in harmony and tension: an integration of studies on intergroup relations (New York, Harper).

Stewart, J. (1996) Local government today (London, Local Government Management Board).

Tollefson, K. D. (1995) Potlatching and political organizations among the Northwest Coast Indians, Ethnology, 34(1), p. 53, 1-21. Available online at: http://search.epnet.com/direct. asp?an $=9505023827 \& \mathrm{db}=$ afh (accessed 18 August 2004).

West, A. \& Pennel, H. (2000) New Labour and school-based education in England: changing the system of funding, British Education Research Fournal, 26(4), 523-536.

Working Group on 14-19 Reform (2004) 14-19 curriculum and qualifications reform [electronic resource], final report of the working group on 14-19 reform (London, DfES). 
